\title{
Papers
}

\section{Antenatal betamethasone and incidence of neonatal respiratory distress after elective caesarean section: pragmatic randomised trial}

Peter Stutchfield, Rhiannon Whitaker, Ian Russell, on behalf of the Antenatal Steroids for Term Elective Caesarean

Section (ASTECS) Research Team

\begin{abstract}
Objective To test whether steroids reduce respiratory distress in babies born by elective caesarean section at term.

Design Multicentre pragmatic randomised trial.

Setting 10 maternity units.

Participants 998 consenting women randomised at decision to deliver by elective caesarean section; 503 randomised to treatment group.

Interventions The treatment group received two intramuscular doses of $12 \mathrm{mg}$ betamethasone in the 48 hours before delivery. The control group received treatment as usual.

Outcome measures The primary outcome was admission to special care baby unit with respiratory distress. Secondary outcomes were severity of respiratory distress and level of care in response.

Results Sex, birth weight, and gestation were not different between the two groups. Of the 35 babies admitted to special baby units with respiratory distress, 24 were in the control group and 11 in the intervention group $(\mathrm{P}=0.02)$. The incidence of admission with respiratory distress was 0.051 in the control group and 0.024 in the treatment group (relative risk $0.46,95 \%$ confidence interval 0.23 to 0.93 ). The incidence of transient tachypnoea of the newborn was 0.040 in the control group and 0.021 in the treatment group $(0.54,0.26$ to 1.12). The incidence of respiratory distress syndrome was 0.011 in the control group and 0.002 in the treatment group $(0.21$, 0.03 to 1.32 ).

Conclusions Antenatal betamethasone and delaying delivery until 39 weeks both reduce admissions to special care baby units with respiratory distress after elective caesarean section at term.
\end{abstract}

\section{Introduction}

The rate of caesarean section in England rose from 9\% in 1980 to $22 \%$ in 2003 as a result of changing practice in the management of previous caesarean and breech presentation as well as increased choice for women. ${ }^{12}$ This increase has included some women who opted for caesarean section at socially convenient times, without medical reasons. ${ }^{3}$ One survey reported that $69 \%$ of consultant obstetricians in England and Wales agree to women's requests for section in the absence of obstetric indications. ${ }^{4}$ Recent guidelines from the National Institute for Clinical Excellence (NICE, now National Institute for Health and Clinical Excellence) have recommended that a woman's request alone is not an indication for caesarean section. ${ }^{5}$
The consequences of elective caesarean section at term for the baby have received little attention. The incidence of respiratory distress is much higher than in vaginal delivery $(0.036 v$ 0.0053). ${ }^{6}$ Other risk factors for respiratory distress include gestational age, mode of delivery, male sex, fetal asphyxia, maternal asthma and diabetes, and type of anaesthesia given during delivery (regional or general).$^{6-9}$ The development of respiratory distress leads to admission to a special care baby unit or neonatal intensive care unit, often at a distance, separation from the mother, and complications from invasive procedures including artificial ventilation.

Antenatal corticosteroids reduce the incidence of respiratory distress in preterm babies. ${ }^{10}$ Guidance has long recommended their routine use when delivery is expected before 34 weeks' gestation. ${ }^{1{ }^{12}}$ However, no trials have been conducted of antenatal corticosteroids in mothers delivered by elective caesarean section at term.

The antenatal steroids for term caesarean section (ASTECS) randomised trial therefore sought to evaluate whether giving the recommended two doses of betamethasone before delivery ${ }^{13}$ reduces the incidence of respiratory distress in babies delivered by elective caesarean section at term. Five studies lasting between three and 20 years, with more than 1500 patients, have shown no adverse effects of a single course of antenatal corticosteroids, neither through infection of fetus or mother nor in long term neurological or cognitive effects. ${ }^{10}{ }^{12}$

\section{Methods}

In 1995 the ASTECS team submitted the protocol to the National Perinatal Trial Centre, started recruitment, and invited other obstetric units to participate. By November 1998, altogether 10 units were taking part.

Mothers were eligible for the trial if elective caesarean section was planned at 37 weeks' gestation or beyond. Exclusion criteria included severe maternal hypertension, history of peptic ulceration, severe fetal rhesus sensitisation, and evidence of intrauterine infection. We used an algorithm from the Confidential Enquiry into Sudden Death in Infancy (CESDI) to calculate gestation from last menstrual period, expected date of delivery, and estimates from first ultrasound scan and at birth. Women who were eligible received an explanation of the study and an information sheet. In the 48 hours before elective caesarean section, women received either two intramuscular doses of $12 \mathrm{mg}$ of

A list of collaborators is on bmj.com 
betamethasone, separated by 24 hours, or treatment as usual, without antenatal steroids.

The trial centre in Rhyl held a list of treatment allocations derived from the random number generator in MS Excel but concealed from all participants. Midwives with signed consent from a mother phoned Rhyl and received the next allocation on the list. They informed the mother and recorded the allocation in her notes. As ASTECS was a pragmatic trial to estimate the effectiveness of betamethasone for caesarean section at term in routine clinical practice, blinding participants and professionals was neither desirable nor possible.

\section{Outcome measures}

The primary outcome was admission to a special care baby unit with respiratory distress. Secondary outcomes were severity of respiratory distress and level of care needed. ${ }^{14}$ To diagnose respiratory distress within 24 hours of birth needed tachypnoea (more than 60 breaths per minute) with grunting, recession, or nasal flaring. From reported arterial gases and oximetry measurements, we graded respiratory distress as mild if the baby received less than 30\% oxygen, severe if it received more than $70 \%$ oxygen or ventilatory support, otherwise moderate. We asked for chest radiographs of babies admitted with respiratory distress. Two neonatal radiologists (David Pilling, consultant radiologist at Alder Hey Children's Hospital, and Alan Sprigg, consultant radiologist at Sheffield Children's Hospital) independently assessed these for the radiological features of transient tachypnoea of the newborn or the reticular granular pattern of respiratory distress syndrome. ${ }^{15}$

\section{Sample size and analysis}

Recruiting 1100 mothers would have yielded $80 \%$ power of detecting a reduction in the percentage of babies admitted to special baby units with respiratory distress from $8 \%$ to $4 \%$ when a $5 \%$ significance level was used. Because antenatal steroids do not reduce respiratory distress syndrome in twin pregnancy, ${ }^{16}$ we analyse only singleton deliveries. Analysis was by intention to treat, $t$ test for normally distributed data, and $\chi^{2}$ test for categorical data, using logistic regression to adjust for confounding variables.

\section{Results}

Recruitment began in Rhyl in February 1995 and another nine centres by November 1998. The last pregnant woman entered the trial in April 2002. Follow-up continued until December 2002, when all babies had left hospital. In all 998 women entered the study-313 from Bradford Royal Infirmary, 233 from Ipswich Hospital, 210 from Glan Clwyd Hospital, 135 from Southmead Hospital, and 107 from the remaining six centres.

Figure 1 shows the flow of participants through the trial. The trial centre received no data after randomisation on 29 women. There were 20 sets of twins, and seven mothers gave birth before 37 weeks' gestation. Hence 942 babies were available for intention to treat analysis, 467 in the treatment group and 475 in the control group. These two groups were similar in mothers' age, asthma, and smoking, and in babies' sex and birth weight (table 1). Eighty six (9.1\%) were born at 37 weeks' working gestation, $434(46.1 \%)$ at 38 weeks, $357(37.9 \%)$ at 39 weeks, $46(4.9 \%)$ at 40 weeks, $13(1.4 \%)$ at 41 weeks, and $6(0.6 \%)$ at 42 or more weeks. Ten women (four in the treatment group) had diabetes: six had gestational diabetes that was controlled by diet, three had type 1 diabetes and one type 2 diabetes. None of their babies developed respiratory distress. In all, 51 women delivered by emergency section before random allocation came into effect.

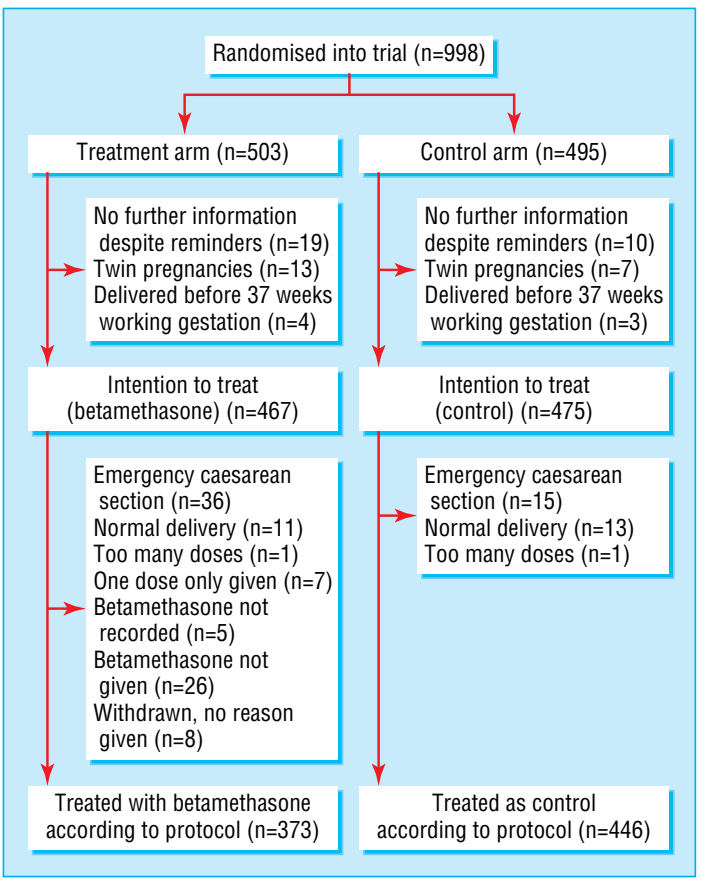

Fig 1 Flow of participants through the trial

\section{Primary outcome: admission to special care baby unit}

Table 2 shows that 35 babies entered these units with respiratory distress, 24 in the control group and 11 in the treatment group $(\mathrm{P}=0.021)$. The incidence of admission with respiratory distress was therefore 0.051 in the control group and 0.024 in the treatment group-a relative risk of 0.46 in favour of treatment $(95 \%$ confidence interval 0.23 to 0.93 ).

\section{Secondary outcomes}

No mother of a control baby admitted to a special care baby unit received general anaesthetic, compared with five $(45 \%)$ in the treatment group $(\mathrm{P}<0.001)$. Three $(12 \%)$ of the control babies so admitted received neonatal resuscitation, compared with eight $(73 \%)$ in the treatment group $(\mathrm{P}<0.001)$. Four $(36 \%)$ of these intervention babies also received ventilation through a mask, and two $(18 \%)$ also received intubation, compared with none in the control group $(\mathrm{P}=0.006$ and $\mathrm{P}=0.09$, respectively). The two groups did, however, not differ significantly with regard to the sex, birth weight, or gestation of infants admitted to a special baby unit.

Table 3 shows that the severity of respiratory distress in babies admitted to special care baby unit was similar in both groups. We received radiographs relating to 22 of the 35 babies admitted with respiratory distress. The remaining 13 babies had diagnoses of transient tachypnoea of the newborn on discharge. Nineteen control babies had transient tachypnoea of the newborn and five had respiratory distress syndrome, compared with 10 treated babies with transient tachypnoea and one with respiratory distress syndrome. The incidence of respiratory distress syndrome was therefore 0.011 in the control group and 0.002 in the treatment group (relative risk $0.21,0.03$ to 1.32), and the incidence of transient tachypnoea of the newborn was 0.040 in the control group and 0.021 in the treatment group $(0.54,0.26$ to 1.12 ).

Only two intervention babies received intensive care-one at level 1 for one day and level 2 (high dependency) for three days, the other at level 2 for one day (fig 2). In contrast, 14 control babies received intensive care; three with respiratory distress 


\begin{tabular}{|c|c|c|c|c|c|c|c|c|c|}
\hline \multirow[b]{2}{*}{ Characteristics } & \multicolumn{3}{|c|}{ Treated according to protocol } & \multicolumn{3}{|c|}{ Not treated according to protocol } & \multicolumn{3}{|c|}{ Total (intention to treat) } \\
\hline & $\begin{array}{l}\text { Betamethasone } \\
\text { group }\end{array}$ & Control group & Total & $\begin{array}{l}\text { Betamethasone } \\
\text { group }\end{array}$ & $\begin{array}{l}\text { Control } \\
\text { group }\end{array}$ & Total & $\begin{array}{l}\text { Betamethasone } \\
\text { group }\end{array}$ & Control group & Total \\
\hline \multicolumn{10}{|l|}{ Binary* } \\
\hline Male baby & 190/373 (51.3) & $\begin{array}{c}229 / 446 \\
(50.9)\end{array}$ & $\begin{array}{c}419 / 819 \\
(51.2)\end{array}$ & 44/94 (43) & $\begin{array}{c}14 / 29 \\
(48)\end{array}$ & $58 / 123$ (47) & $234 / 467(50.1)$ & $\begin{array}{c}243 / 475 \\
(51.2)\end{array}$ & $\begin{array}{c}477 / 942 \\
(50.6)\end{array}$ \\
\hline Maternal asthma & $33 / 373(8.8)$ & $53 / 446(11.9)$ & $\begin{array}{r}86 / 819 \\
(10.5) \\
\end{array}$ & $11 / 94(12)$ & $5 / 29(17)$ & $16 / 123(13)$ & 44/467 (9.4) & $58 / 475$ (12.2) & $\begin{array}{c}102 / 942 \\
(10.8) \\
\end{array}$ \\
\hline Maternal smoking & 63/373 (16.9) & $\begin{array}{c}101 / 446 \\
(22.6)\end{array}$ & $\begin{array}{c}164 / 819 \\
(20.0)\end{array}$ & $26 / 94$ (28) & $9 / 29$ (31) & $35 / 123$ (28) & $89 / 467(19.1)$ & $\begin{array}{c}110 / 475 \\
(23.2)\end{array}$ & $\begin{array}{c}199 / 942 \\
(21.1)\end{array}$ \\
\hline General anaesthetic & 28/372 (7.5) & $24 / 443(5.4)$ & $\begin{array}{c}52 / 815 \\
(6.4)\end{array}$ & 14/83 (17) & $2 / 15(13)$ & $16 / 98$ (16) & $42 / 455(9.2)$ & $26 / 458(5.7)$ & $68 / 913(7.4)$ \\
\hline \multicolumn{10}{|l|}{ Quantitative† } \\
\hline Mother's age (years) & $31.1(5.2)$ & $30.6(5.2)$ & $30.8(5.2)$ & $30.8(5.0)$ & $29.8(4.8)$ & $30.6(4.9)$ & $31.1(5.2)$ & $30.5(5.1)$ & $30.9(5.2)$ \\
\hline Birth weight (g) & $3280(450)$ & $3320(470)$ & $\begin{array}{l}300 \\
(460)\end{array}$ & $3170(490)$ & $\begin{array}{l}3310 \\
(550)\end{array}$ & $3200(500)$ & $3260(470)$ & $3320(470)$ & $3290(470)$ \\
\hline Working gestation (days) & $269(5.3)$ & $269(5.3)$ & $269(5.3)$ & $269(7.9)$ & $\begin{array}{c}272 \\
(11.2)\end{array}$ & $270(8.8)$ & $269(5.9)$ & $269(5.9)$ & $269(5.9)$ \\
\hline Corrected gestation (days) & $261(6.6)$ & $269(6.3)$ & $269(6.4)$ & $269(6.8)$ & $\begin{array}{c}272 \\
(10.3)\end{array}$ & $270(7.8)$ & $269(6.7)$ & $270(6.6)$ & $269(6.6)$ \\
\hline
\end{tabular}

*Values are numbers (percentages). Denominator varies according to number of valid responses. †Values are means (standard deviations).

syndrome required ventilation for between two and five days and stays of between 12 and 18 days. Antenatal betamethasone thus substantially reduced resource use in special baby units.

The logistic regression model in figure 3 predicts the probability of admission to special care baby unit with respiratory distress from the gestational age of the baby. The predicted probability of admission at 37 weeks was $11.4 \%$ in the control group and 5.2\% in the treatment group, at 38 weeks it was $6.2 \%$ and $2.8 \%$, respectively, and at 39 weeks it was $1.5 \%$ and $0.6 \%$

\section{Adverse effects}

Reports of side effects came from seven mothers in the treatment group who had received two doses of betamethasone and one who had received only one. Five reported generalised flushing, one nausea, one tenderness at the injection site, and one increased energy with difficulty in sleeping. No such reports came from the control group. No reports were made of wound infection or neonatal sepsis.

Table 2 Outcomes by group

\begin{tabular}{|c|c|c|c|c|c|c|c|c|c|}
\hline \multirow[b]{2}{*}{ Outcomes* } & \multicolumn{3}{|c|}{ Treated according to protocol } & \multicolumn{3}{|c|}{ Not treated according to protocol } & \multicolumn{3}{|c|}{ Total (intention to treat) } \\
\hline & $\begin{array}{l}\text { Betamethasone } \\
\text { group }\end{array}$ & $\begin{array}{l}\text { Control } \\
\text { group }\end{array}$ & $\begin{array}{l}\text { Net benefit from } \\
\text { steroid ( } 95 \% \\
\text { confidence } \\
\text { interval) }\end{array}$ & $\begin{array}{l}\text { Betamethasone } \\
\text { group }\end{array}$ & $\begin{array}{l}\text { Control } \\
\text { group }\end{array}$ & $\begin{array}{l}\text { Net benefit from } \\
\text { steroid ( } 95 \% \\
\text { confidence } \\
\text { interval) }\end{array}$ & $\begin{array}{l}\text { Betamethasone } \\
\text { group }\end{array}$ & Control group & $\begin{array}{l}\text { Net benefit from } \\
\text { steroid ( } 95 \% \\
\text { confidence interval) }\end{array}$ \\
\hline \multicolumn{10}{|l|}{ Binary $^{*}$} \\
\hline Resuscitated & $31 / 373(8.3)$ & $\begin{array}{c}46 / 446 \\
(10.3)\end{array}$ & $2.0(-2.1$ to 6.0$)$ & 13/94 (14) & $8 / 29(28)$ & 14 (-2 to 33$)$ & $44 / 467 \quad(9.4)$ & $54 / 475(11.4)$ & 2.0 (-2.0 to 6.0$)$ \\
\hline \multicolumn{10}{|l|}{ Resuscitation: } \\
\hline Mask ventilation & $15 / 373(4.0)$ & $\begin{array}{c}17 / 446 \\
(3.8)\end{array}$ & $0.2(-2.5$ to 3.1$)$ & $7 / 94(7)$ & $3 / 29(10)$ & $3(-7$ to 20$)$ & $22 / 467(4.7)$ & $20 / 475(4.2)$ & -0.5 (-3.3 to 2.2$)$ \\
\hline Intubation & $2 / 373(0.5)$ & $\begin{array}{r}1 / 446 \\
(0.2)\end{array}$ & $0.3(-0.7$ to 1.7$)$ & 2/94 (2) & $0 / 29(0)$ & $-2(-10$ to 8$)$ & $4 / 467 \quad(0.9)$ & $1 / 475(0.2)$ & -0.6 (-2.0 to 0.4$)$ \\
\hline $\begin{array}{l}\text { Admitted to special } \\
\text { care baby unit } \\
\text { with respiratory } \\
\text { distress }\end{array}$ & $7 / 373(1.9)$ & $\begin{array}{c}22 / 446 \\
(4.9)\end{array}$ & 3.1 (0.6 to 5.7$)$ & 4/94 (4) & $2 / 29(7)$ & $3(-5$ to 18$)$ & $11 / 467(2.4)$ & $24 / 475(5.1)$ & 2.7 (0.3 to 5.3$)$ \\
\hline \multicolumn{10}{|l|}{ Quantitative† } \\
\hline $\begin{array}{l}\text { Apgar score at } 1 \\
\text { minute }\end{array}$ & $8.53(0.07)$ & $\begin{array}{l}8.59 \\
(0.05)\end{array}$ & $\begin{array}{c}-0.06 \\
(-0.23 \text { to } 0.10)\end{array}$ & $8.27(0.20)$ & $8.14(0.32)$ & $\begin{array}{c}0.13 \\
(-0.67 \text { to } 0.93)\end{array}$ & $8.48(0.07)$ & $8.57(0.05)$ & $-0.09(-0.26$ to 0.08$)$ \\
\hline $\begin{array}{l}\text { Apgar score at } 5 \\
\text { minutes }\end{array}$ & $9.36(0.05)$ & $\begin{array}{l}9.30 \\
(0.05)\end{array}$ & $\begin{array}{c}0.05 \\
(-0.09 \text { to } 0.20)\end{array}$ & $8.94(0.24)$ & $9.10(0.21)$ & $\begin{array}{c}-0.18 \\
(-1.05 \text { to } 0.72)\end{array}$ & $9.27(0.06)$ & $9.29(0.05)$ & $-0.02(-0.18$ to 0.14$)$ \\
\hline $\begin{array}{l}\text { Time in special } \\
\text { care baby unit in } \\
\text { days }\end{array}$ & $0.14(0.05)$ & $\begin{array}{l}0.32 \\
(0.09)\end{array}$ & $\begin{array}{c}0.18 \\
(-0.02 \text { to } 0.37)\end{array}$ & $0.33(0.14)$ & $0.93(0.42)$ & $\begin{array}{c}0.60 \\
(-0.53 \text { to } 1.73)\end{array}$ & $0.18(0.05)$ & $0.35(0.09)$ & $0.18(-0.02$ to 0.37$)$ \\
\hline $\begin{array}{l}\text { Time on oxygen in } \\
\text { hours }\end{array}$ & $0.74(0.43)$ & $\begin{array}{c}2.80 \\
(1.12)\end{array}$ & $\begin{array}{c}2.06 \\
(-0.31 \text { to } 4.43)\end{array}$ & $0.27(0.17)$ & $\begin{array}{l}13.24 \\
(9.14)\end{array}$ & $\begin{array}{c}12.98 \\
(-6.02 \text { to } 31.97)\end{array}$ & $0.64(0.35)$ & $3.44(1.20)$ & 2.80 (0.34 to 5.25$)$ \\
\hline $\begin{array}{l}\text { Maximum inspired } \\
\text { oxygen } \\
\text { concentration in } \\
\%\end{array}$ & $21.27(0.16)$ & $\begin{array}{l}21.93 \\
(0.33)\end{array}$ & $\begin{array}{c}0.65 \\
(0.19 \text { to } 1.42)\end{array}$ & $21.35(0.19)$ & $\begin{array}{l}22.76 \\
(1.22)\end{array}$ & $\begin{array}{c}1.37 \\
(-0.47 \text { to } 4.39)\end{array}$ & $21.29(0.13)$ & $21.99(0.31)$ & 0.68 (0.12 to 1.42$)$ \\
\hline
\end{tabular}




$\begin{aligned} & \text { Table } \mathbf{3} \text { Reason for admission to special care baby unit by group } \\
& \text { Beason for admission }\end{aligned}$
\begin{tabular}{lcc} 
Betamethasone group & Control group \\
\hline Respiratory distress by severity: & 4 & 9 \\
\hline Mild & 6 & 10 \\
\hline Moderate & 1 & 5 \\
\hline Severe & & 19 \\
\hline Respiratory distress by type: & 10 & 5 \\
\hline Transient tachypnoea of the newborn & 1 & $\mathbf{3 2}$ \\
\hline Respiratory distress syndrome & $\mathbf{2 6}$ & 24 \\
\hline Total No of babies admitted & 11 & 8 \\
\hline With respiratory distress (subtotal) & 15 & \\
\hline Other (without respiratory distress) & & \\
\hline
\end{tabular}

\section{Discussion}

Betamethasone given immediately before elective caesarean section at term reduces respiratory distress and admission to a special care baby unit. The rate of such admission was 0.050 in the control group and 0.024 in the treatment group. This rate falls with increasing gestation, supporting the recommendation to delay elective caesarean section until the 39th week. ${ }^{6}$ Nevertheless, the benefits of antenatal steroids persist until 39 weeks.

\section{Strengths and weaknesses of the trial}

We designed ASTECS as a pragmatic trial to estimate the effectiveness of betamethasone for caesarean section at term in routine practice in 10 diverse maternity units. Blinding participants and professionals was therefore neither desirable nor possible. Similarly the use of placebos was not practical. Furthermore the primary outcome, respiratory distress requiring admission to special care baby unit, is hardly susceptible to maternal influence.

To simplify, and thus increase, recruitment we did not stratify treatment allocation by gestation or centre; no imbalance in allocation resulted. The need to alter clinical practice to permit two injections in the 48 hours before delivery slowed recruitment to the trial, which finished before reaching its target; nevertheless, the trial detected significant differences between groups. Although race reportedly modifies the effect of antenatal steroids, the evidence is conflicting. ${ }^{76}$ The trial lacked power to tackle this secondary issue.

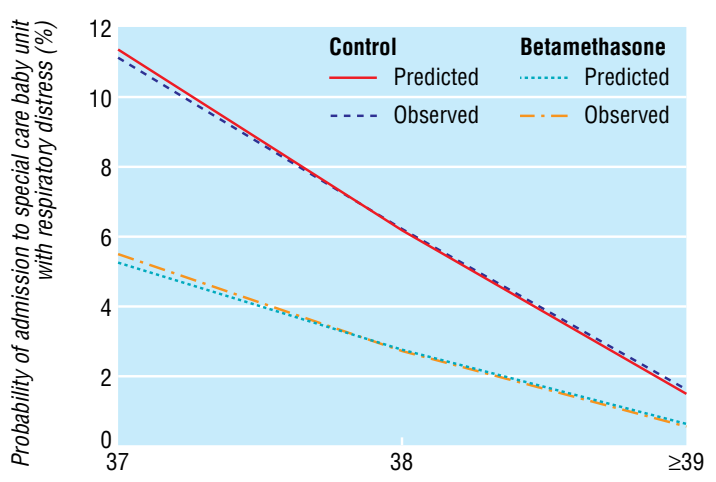

Calculated gestation (weeks)

Fig 3 Probability of admission to special care baby unit with respiratory distress by gestation (observed and predicted by logistic model): intention to treat analysis. Logistic regression model: $z=-5.034+2.139$ (if baby is 37 weeks) +1.472 (if baby is 38 weeks) +0.840 (if mother was not randomised to receive betamethasone) where the default is randomised to receive betamethasone at 39 weeks. Predicted probability=exp $(\mathrm{z}) /[1+\exp (\mathrm{z})]$

\section{Unanswered questions}

Reducing the number of babies born by elective caesarean section before 39 weeks' gestation will reduce admissions with respiratory distress to special care baby units. However, many clinical factors influence the timing of elective caesareans. There may be uncertainty regarding gestation, medical indications for earlier delivery, and concerns about spontaneous onset of labour resulting in emergency caesareans with risks for mother and baby. ${ }^{17}$ Social factors also influence timing. ${ }^{4}$ Plans for changing clinical management should take all these factors into account.

\section{Meaning of the study}

Independent radiological review confirmed that antenatal betamethasone reduced the incidence of transient tachypnoea of the newborn from $4 \%$ of elective caesarean sections to $2.1 \%$ and that of respiratory distress syndrome from $1.1 \%$ to $0.2 \%$. To our knowledge this is the first report that antenatal steroids prevent transient tachypnoea. During labour and at birth, the mature lung switches from active chloride and fluid secretion to active

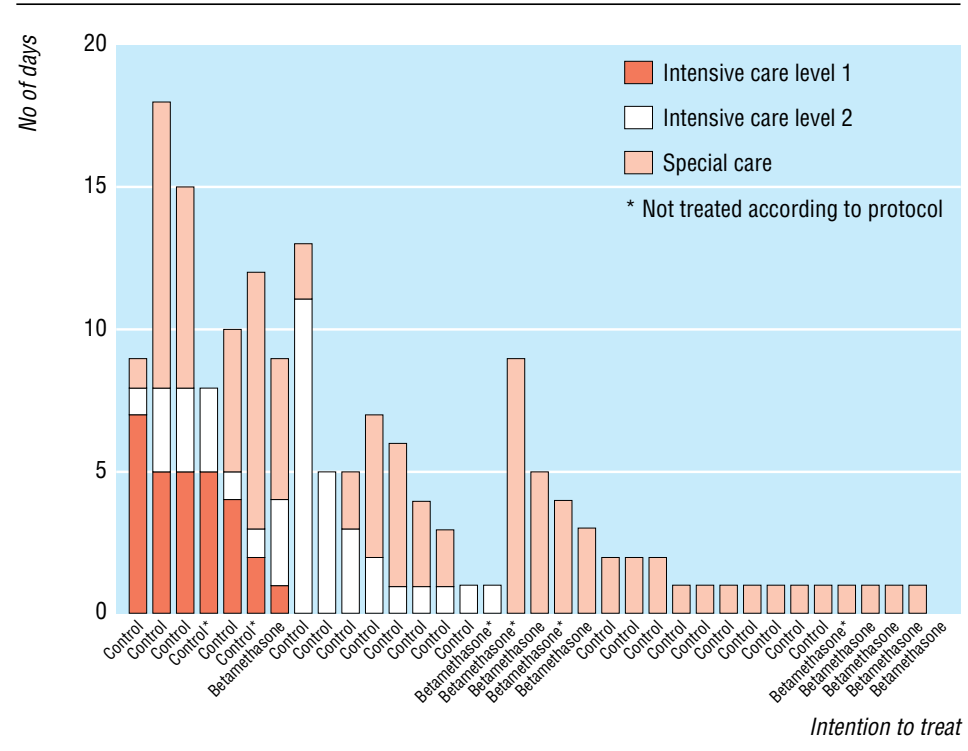

Fig 2 Babies admitted to a special care baby unit in descending order of intensity of care and of length of stay: intention to treat analysis 


\section{What is already known on this topic}

Two antenatal doses of betamethasone reduce the incidence of respiratory distress syndrome by more than $50 \%$ in babies born before 34 weeks' gestation, thus reducing morbidity and mortality

Although this is now recommended practice, the treatment is considered of no benefit beyond this gestational age

The treatment's effect is thought to be mediated through increased surfactant production, a shortage of which leads to respiratory distress syndrome, which is common in preterm babies

Long term studies have shown no harmful effect of a single course of betamethasone

\section{What this study adds}

Babies born after 37 weeks by elective caesarean section also benefit from antenatal betamethasone

This reduces the incidence of respiratory distress by more than $50 \%$, mainly by reducing transient tachypnoea of the newborn

These findings imply that antenatal steroids can aid the clearing of lung fluid after delivery

When counselling a mother before elective caesarean section at term, the increased risk of admission with respiratory distress should be considered

The likely benefits of antenatal betamethasone should be compared with those of delaying caesarean section until 39 weeks when possible

sodium and fluid absorption. ${ }^{18-20}$ The reduced incidence of transient tachypnoea in the steroid group is consistent with the hypothesis that corticosteroids, increased in mother and fetus through the stress of labour, encourage the expression of the epithelial channel gene and allow the lung to switch from fluid secretion to fluid absorption. Without another source of corticosteroid, elective caesarean section will disrupt this process. Thereafter admission with respiratory distress to a special unit separates mother and baby, potentially disrupting bonding, and increasing the cost of care and the risk of complications. ${ }^{21}{ }^{22}$ Furthermore, neonatal respiratory morbidity increases the risk of asthma in childhood. ${ }^{23}$

\section{Conclusion}

Antenatal betamethasone is effective in reducing admission to special care baby unit with respiratory distress after elective caesarean section at term. In planning elective caesareans, the risk of respiratory distress should be considered and the likely benefits of antenatal corticosteroids should be compared with those of delaying delivery until 39 weeks when possible.

We thank all participants-patients, staff, and collaborators-for their contributions. For funding we thank the NHS: the Wales Office of Research and Development in health and social care (WORD) and Conwy and Denbighshire NHS Trust.

Contributors: Authors and other members of the ASTECS trial team contributed as follows. PS is consultant paediatrician and neonatologist at Glan Clwyd Hospital, which provides a neonatal intensive care service for North Wales. He developed the protocol, initiated and coordinated the trial, recruited other centres, supervised collection, validation and analysis of data, and drafted this paper. He guarantees its clinical content. Philip Banfield, consultant obstetrician at Glan Clwyd Hospital, recruited patients to the trial. Jeff Berry and James Satelle, information analysts at Glan Clwyd Hospital, developed and managed the trial database. Nigel Bickerton, consultant obstetrician at Glan Clwyd Hospital, contributed to the protocol and recruited patients to the trial. Duncan Cameron, consultant paediatrian and neonatologist at Glan Clwyd Hospital, contributed to the protocol, the newsletter for participating centres and data collection. Lesley Furneaux, personal secretary to PS, acted as research coordinator, randomising patients, collating and entering data, and checking their completeness. David Pilling, consultant radiologist at Alder Hey Children's Hospital, and Alan Sprigg, consultant radiologist at Sheffield Children's Hospital, independently assessed the chest radiographs submitted. IR contributed to analysing, interpreting, and writing this paper. He guarantees its statistical content. RW validated and analysed data, and contributed to interpreting and writing this paper. Matouk Zbaeda, previously senior paediatric registrar at Glan Clwyd Hospital, reviewed elective caesarean sections at term, thus stimulating the trial, and contributed to the protocol.

Funding: Wales Office of Research and Development in health and social care (WORD) and Conwy and Denbighshire NHS Trust.

Competing interests: None declared.

Ethical approval: North West Multi-centre Research Ethics Committee and the 10 relevant local research ethics committees approved the trial protocol.

1 Royal College of Obstetricians and Gynaecologists Clinical Effectiveness Unit. The national sentinel caesarean section audit report. London: RCOG Press, 2001.

2 Department of Health. NHS maternity statistics, England: 2002-3. London: DoH, 2004. (Bulletin 2004/10.)

3 Doctors told to curb "posh" caesareans. Sunday Times 2004 April 25:14.

4 Cotzias CS, Paterson-Brown S, Fisk NM. Obstetricians say yes to maternal request for elective caesarean section: a survey of current opinion. Eur J Obstet Gynaecol Reprod Biol elective caesar

5 National Collaborating Centre for Women and Children's Health. Caesarean section clinical guideline. London: RCOG Press, 2004.

6 Morrison JJ, Rennie JM, Milton PJ. Neonatal respiratory morbidity and mode of delivery at term: influence of timing of elective caesarean section. $\mathrm{Br} J$ Obstet Gynaecol 1995; 102:101-6.

7 Robert ME, Neff RK, Hubbell JP, Taeusch HW, Avery ME. Association between maternal diabetes and the respiratory distress syndrome in the newborn. $N$ Engl J Med 1976;294:357-60.

8 Schatz M, Zeiger RS, Hoffman CP, Saunders BS, Harden KM, Forsythe AB. Increased transient tachypnoea of the newborn in infants of asthmatic mothers. Am J Dis Child 1991;145:156-8

9 Demissie K, Marcella SW, Breckenridge MB, Rhoads GG. Maternal asthma and transient tachypnoea of the newborn. Pediatrics 1998;102:84-90.

10 Crowley P. Prophylactic corticosteriods for preterm birth. Cochrane Database Syst Rev 2000;(2):CD000065.

11 Crowley P, Chalmers I, Keirse MJNC. The effects of corticosteroid administration before preterm delivery: an overview of the evidence from controlled trials. Br J Obstet Gynaecol 1990;97:11-25.

12 Royal College of Obstetricians and Gynaecologists Scientific Advisory Committee. RCOG guidelines No 7: antenatal corticosteroids to prevent respiratory distress syndrome. 2nd ed. London: RCOG Press, 2004:1-9.

13 McCarthy M. Recommendations for antenatal corticosteroids. Lancet 1994;343:726.

13 McCarthy M. Recommendations for antenatal corticosteroids. Lancet 1994;343:726.
14 Report of working group of the British Association of Perinatal Medicine and Neona-

Report of working group of the British Association of Perinatal Medicine and Neona-
tal Nurses Association on categories of babies requiring neonatal care. Arch Dis Child tal Nurses Assoc
$1992 ; 67: 868-9$.

15 Avery ME, Gatewood OB, Brumley G. Transient tachypnoea of newborn. Am J Dis Child 1966;111:380-5.

16 Quist-Therson EC, Myhr TL, Ohlsson A. Antenatal steroids to prevent respiratory distress syndrome; multiple gestation as an effect modifier. Acta Obstet Gynecol Scand 1999;78:388-92.

17 Hillan EM. Postoperative morbidity following caesarean delivery. $J$ Adv Nurs $1995 ; 22: 1035-42$.

18 Watlers DV, Oliver RE. The role of catecholamines in lung fluid absorption at birth. Pediatr Res 1978;12:239-42.

19 Rimmer S, Fawcitt J. Delayed clearance of pulmonary fluid in the neonate. Arch Dis Rimmer S, Fawcitt J.

20 O'Brodovich HM. Immature epithelial $\mathrm{Na}^{+}$channel expression is one of the pathogenetic mechanisms leading to human neonatal respiratory distress syndrome. Proc Assoc Am Physicians 1996;108:345-55

21 Symanski ME. Maternal-infant bonding, practice issues for the 1990s. J Nurs Midwifery 1992;37:2:67S-73S

22 Madar J, Richmond S, Hey E. Surfactant deficient respiratory distress after elective delivery at 'term'. Acta Paediatr 1999;88:1244-8.

23 Smith GC, Wood AM, White IR, Pell JP, Cameron AD, Dobbie R. Neonatal respiratory morbidity at term and the risk of childhood asthma. Arch Dis Child 2004;89:956-60.

(Accepted 27 June 2005)

doi 10.1136/bmj.38547.416493.06

Conwy and Denbighshire NHS Trust, Glan Clwyd Hospital, Rhyl, Denbighshire LL18 5UJ

Peter Stutchfield consultant paediatrician

Institute of Medical and Social Care Research, University of Wales Bangor LL57 
Papers

2PX

Correspondence to: P Stutchfield DrPeter.Stutchfield@cd-tr.wales.nhs.uk

Rhiannon Whitaker trial statistician 